\title{
Variation of the milling conditions in the obtaining of nanocellulose from the paper sludge
}

Fabiany Sayuri Kano ${ }^{1}$, Alana Gabrieli de Souza ${ }^{1}$, Derval dos Santos Rosa ${ }^{1}$

\author{
${ }^{1}$ Environmentally Friendly Polymers Laboratory - Federal University of ABC , CEP: 09210-580, Santo André, São Pau- \\ lo, Brazil. \\ e-mail: fabiany_92@hotmail.com, alana_gs@live.com,dervalrosa@yahoo.com.br
}

\begin{abstract}
This work aimed to evaluate three different milling conditions, seeking the optimization of CNS isolation process. The paper sludge was chemically treated with detergent and $\mathrm{H}_{2} \mathrm{O}_{2}$, by two steps, to remove the noncellulosic contents (hemicellulose and lignin). After these treatments, the sample was milled with the variation of a liquid medium. The three liquids milling medium were: i) dry medium (CNS-D); ii) moist with water and (CNS-W) iii) moist with ethanol (CNS-E). The CNSs were characterized by Fourier transform infrared spectroscopy (FTIR), thermogravimetric analysis (TGA), scanning electron microscopy (SEM), zeta potential and dynamic light scattering (DLS). The milled samples presented different behavior, depending on the medium applied. The CNS-W presented low efficiency due to the formation of agglomerates around the ceramic ball, resulting in larger fiber sizes (microsizes). Although, the samples CNS-D and CNS-E presented similar behavior of sizes distribution, with average size $340 \mathrm{~nm}$ and $373 \mathrm{~nm}$, respectively, determined by DLS. The CNS-E sample presented higher yield and electrostatic stability in solution, besides not presenting loss of crystallinity, as occurred with CNS-D, observed by FTIR analysis. Thus, the isolation with ethanol showed more efficient process among the three processes studied. This work achieved the isolation of CNS; besides, it proposed an environmentally friendly isolation method, and this may add value in the paper sludge.
\end{abstract}

Keywords: industrial residue, cellulose nanostructures, ball mill, cellulose characterization.

\section{INTRODUCTION}

A demographic and economic expansion has demanded a greater need for natural resources around the world, and, also, the generation of solid waste is growing. The high waste production is becoming a major social, economic, and environmental problem. Thus, it is necessary to search for alternative solutions that reduce these discards and their impacts, in an environmentally friendly and low-cost way [1-3].

The paper industry is one of the most important in the world, with significant annual paper production. Brazilian is the second biggest producer of cellulose in the world, and paper production in 2016 totaled 10.3 million tons [4]. However, this industry presents the high generation of waste during the processes. The production of one ton of paper generates about $50 \mathrm{~kg}$ of sludge (primary waste). This waste is usually destined for landfills or incinerated, resulting in soil contamination and/or the generation of polluting gases[3,5,6]. Considering that wood is the main raw material used to obtain paper, these residues have a large amount of lignocellulosic material in their composition, which allows their application in other industrial areas. One example is the chemical conversion of paper industry effluents in carboxymethyl cellulose [7]. Besides, this material can also be used to obtain cellulose nanostructures (CNSs).

Nanocellulose material has attracted considerable interest from the research community, government agencies, and industries in recent years. This interest is related to the intrinsic properties of CNSs, such as high mechanical strength and surface area, renewability, it is a non-toxic and biodegradable material. In addition, there is the possibility of producing CNSs from a multitude of sustainable, widely available and lowcost resources such as forest residues (wood saw-dust - pine and eucalyptus), agricultural (wheat straw, sugar cane) and industrial (cotton waste, paper waste, and tobacco industry) [2,8-12]. CNSs can be applied in a variety of areas, such as electronic displays, paints, packaging, membranes, implants, polymer composites and others [13]. The application is highly dependent on the nanocellulose properties and its surface chemistry [14].

There are different methods to isolate cellulose nanostructures, such as acid hydrolysis, enzymatic hydrolysis, mechanical milling, cryocrushing, high-intensity ultrasonication, and others [15]. The different iso- 
lation methods result in different morphologies and aspect ratio, surface characteristics, crystallinity, thermal stability, among others. The most common isolation method is the acid hydrolysis with strong acids, for example, $64 \mathrm{wt} . \%$ sulfuric acid. However, this process can be environmentally hazardous due to the generation of acid effluents [16]. An alternative to isolation is the mechanical method, with emphasis on the methodology of ball milling. This method is considered environmentally friendly because it does not use hazardous chemical reagents [17].

In this work, CNSs were isolated from the primary waste of the paper industry. It also compared three different medium of ball milling to evaluate the better condition of milling, aiming at optimizing the process. This study is still little investigated, to obtain a high productivity process and may be suitable on an industrial scale.

\section{MATERIALS AND METHODS}

\subsection{Raw Material}

The primary paper residue was used as raw material. It was provided by Multiverde Papéis Especiais Ltda. Company (Mogi das Cruzes, Brazil). This residue presented pH=9.3 and sulfide content of $456 \mathrm{mg} . \mathrm{kg}^{-1}$. It was maintained at $60^{\circ} \mathrm{C}$ in an air circulation oven for 5 days until dry.

\subsection{Processing}

The raw material was treated to remove non-cellulosic content. The first step was done with a detergent solution. The second step of treatment was done with a basic oxidative solution, as described below. After the treatments, the sample was converted in cellulose nanostructure using ball mill. The isolation of nanocellulose was done in three different conditions, with a variation in the liquid medium: dry, wet with distilled water and moist with ethanol.

\subsubsection{Treatment of raw material}

The first step of treatment was done with commercial detergent. The detergent treatment was chosen based on previous studies and the efficiency of pretreatment. Other pre-treatments were investigated, as reported by Souza et al., 2017 and Souza et al., 2019 [18,19]. In this stage was used aqueous solution with 5\% (v/v) of commercial neutral detergent. $1 \mathrm{~g}$ of residue was mixed with $10 \mathrm{~mL}$ of solution, in magnetic stirring at $80{ }^{\circ} \mathrm{C}$ for $3 \mathrm{~h}$. After the treated residue was washed, filtered and dried at $70{ }^{\circ} \mathrm{C}$ for $4 \mathrm{~h}$.

After the detergent treatment, the sample was submitted for bleaching treatment. $1 \mathrm{~g}$ of the treated samples were mixed with $20 \mathrm{ml}$ of a solution composed by $34 \%(\mathrm{v} / \mathrm{v})$ hydrogen peroxide $\left(\mathrm{H}_{2} \mathrm{O}_{2}\right)$ and 4 wt $\%$ $\mathrm{NaOH}$ aqueous solution, in magnetic stirring at $50{ }^{\circ} \mathrm{C}$ for $1 \mathrm{~h}$. Then the samples were washed by distilled water, filtered and dried at $70{ }^{\circ} \mathrm{C}$ for $4 \mathrm{~h}$.

\subsubsection{Isolation of cellulose nanostructure}

After the treatments, the sample was milled in a ball mill (Marconi MA500 - $200 \mathrm{rpm}$ ) with a variation of three different milling medium. The liquid milling medium were: i) dry medium (CNS-D); ii) moist with water and (CNS-W) iii) moist with ethanol (CNS-E).

For the milling medium containing water, the sample was mixed with distilled water in a ratio of $1: 1$ (w/v). For the ethanol milling medium, the sample was mixed with ethanol $(80 \%)$ in a ratio of $1: 1(\mathrm{w} / \mathrm{v})$.

All medium milling condition has submitted a jar loaded with alumina balls (diameter of $21 \mathrm{~mm}$ ) and treated the material in a ratio of 60:1. The jar was filled with a third of the material and ball. Then the samples were milled for 6 hours.

For each liquid milling medium was added $10,0 \mathrm{~g}$ of treated material, and its yield was calculated after milling.

\subsection{Characterization}

\subsubsection{Chemical composition}

The extractives, hemicelluloses, cellulose, lignin and ash contents were determined. The Technical Association of Pulp and Paper Industry (TAPPI) standards TAPPI T222 om-02 for lignin and TAPPI T203 cm-99 for hemicelluloses and cellulose were used. 


\subsubsection{Fourier transform infrared spectroscopy (FTIR)}

The equipment used to FTIR analysis was Frontier 94942 (PerkinElmer, USA). Using attenuated total reflectance, the spectra were recorded in the $500-4000 \mathrm{~cm}^{-1}$ range, with 64 scans.

\subsubsection{Thermogravimetric analysis (TGA)}

Thermogravimetric analysis was done to evaluate the thermal stability by a progressive increase of the temperature in the equipment STA 6000 , PerkinElmer (USA). The samples were heated from 30 to $600{ }^{\circ} \mathrm{C}$ with a heating rate of $10^{\circ} \mathrm{C} / \mathrm{min}$ under a nitrogen flow.

\subsubsection{Zeta potential and Dynamic light scattering (DLS)}

The analyses were performed using the Zetasizer Nano ZS equipment (Malvern Instruments, Malvern, UK). The zeta potential $(\zeta)$ of the nanoparticles was determined by electrophoretic mobility measurements and the conversion of the values using the Henry equation.

DLS is a well-established, non-invasive method to measure particles in a dispersed medium, and it is a widely used analysis for the average size calculation of cellulosic nanoparticles. It measures the translational diffusion coefficient of particles in water, which undergo Brownian motion [20]. The hydrodynamic radius is calculated with Stokes-Einstein relation and is obtained as an approximated sphere size of the nanocellulose dispersed in water. Stokes-Einstein equation can be applied only for non-interacting spherically shaped particles. The information was obtained using a dynamic light scattering system (ALV-CGS3) with $90^{\circ}$ fixed scattering angle. A HeNe polarized laser $(22 \mathrm{~mW})$ with a wavelength of $633 \mathrm{~nm}$ was used.

\subsubsection{Scanning electron microscopy (SEM)}

The surface morphologies of powder samples were analyzed by SEM (JEOL - JCM 600, $20 \mathrm{kV}$ ). The samples were covered with gold by sputtering equipment (SCANCOAT, PIRANI 501) at a pressure of $0.3 \mathrm{mbar}$ at $1.5 \mathrm{kV}$ for $60 \mathrm{~s}$, to obtain a nanolayer of $20 \mathrm{~nm}$.

\section{RESULTS AND DISCUSSION}

\subsection{Chemical Composition}

The analysis of the chemical composition of the sample after the treatments was done to verify the efficiency of these treatments in the removal of non-cellulosic components. Table 1 shows the percentage of lignocellulosic components before and after the treatments. Figure 1 represents what is expected after the treatments, with an illustration of the removal of the non-cellulosic components.

Table 1: Lignocellulosic contents of paper sludge before and after the treatments.

\begin{tabular}{c|c|c|c|c|c}
\hline SAMPLE & EXTRACTIVES (\%) & HEMICELLULOSE (\%) & LIGNIN (\%) & CELLULOSE (\%) & ASH (\%) \\
\hline Paper sludge & $4.5 \pm 0.4$ & $20.3 \pm 0.8$ & $19.3 \pm 2.8$ & $34.3 \pm 2.8$ & $21.6 \pm 0.5$ \\
\hline Sample after treatments & $1.4 \pm 0.2$ & $7.7 \pm 0.9$ & $5.4 \pm 1.9$ & $68.0 \pm 3.2$ & $17.5 \pm 1.9$ \\
\hline
\end{tabular}

After treatments occurred a reduction of $69 \%$ of extractives, $62 \%$ of hemicellulose and $72 \%$ of lignin, so, these reductions increase in $98 \%$ on the percentage of cellulose content.

The treatments were done to remove the non-cellulosic content (extractives, hemicellulose, and lignin). This allows greater accessibility to the cellulosic surface, facilitating the fibrillation, thus increasing the efficiency and decreasing the energy consumed during the milling process to obtain the cellulose nanostructures $[21,22]$. 


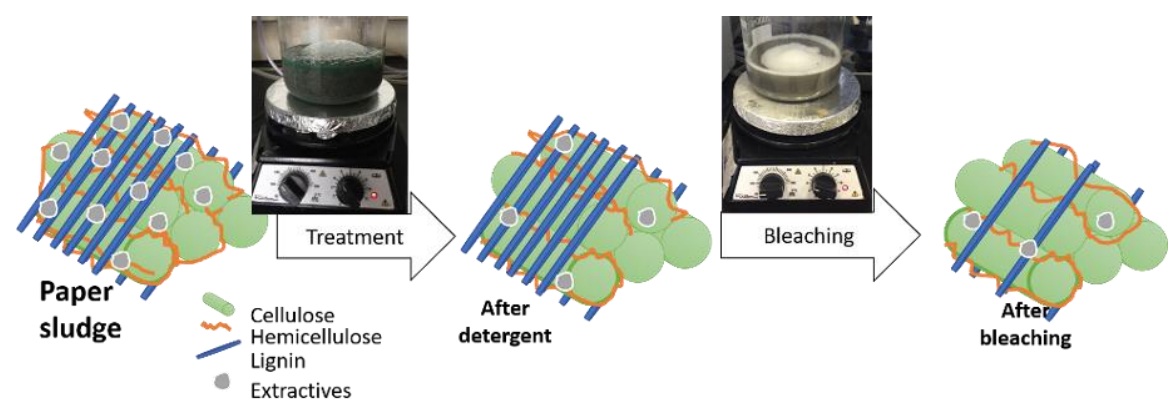

Figure 1: Scheme of the effect of treatments for the non-cellulosic components' removal.

The treatment with commercial detergent aimed the removal of extractives presents on the surface of fibers (waxes and oils). This first treatment influences in the bleaching efficiency, which is the second treatment. It occurs due to the higher exposure of the cellulose fibers obtained, facilitating the access of the bleaching agent and potentializing the action of the $\mathrm{H}_{2} \mathrm{O}_{2}$ solution. The $\mathrm{H}_{2} \mathrm{O}_{2}$ molecules act on the decomposition and oxidation of the lignin molecules, through the cleavage of the ether bond of the polyphenolic compounds [23]. After the treatments, it is observed that a small amount of hemicellulose and lignin remain after bleaching. This is due to the strong interaction of lignin with other polysaccharides (cellulose and hemicellulose), forming complex networks that are difficult to remove completely[24].

All the samples analyzed showed significant ash contents due to the strong chemical treatments used in the paper industry. According to the company's report (characterization of waste according to NBR 10004), these ashes can have in their composition sulfides, fluoride, chloride, aluminum, copper, kaolinite, and others [25]. It can influence the purity of the nanocellulose, which affects directly future applications. In this case, it is not possible to affirm that the CNS are biocompatible. For this statement, further studies involving cytotoxicity and involving microorganisms are needed.

\subsection{After milling - Cellulose nanostructure}

After milling the samples were presented as powders, with different aspects, as shown in Figure 2. It is possible to compare the aspect of the milled samples with the paper sludge in the initial aspect.
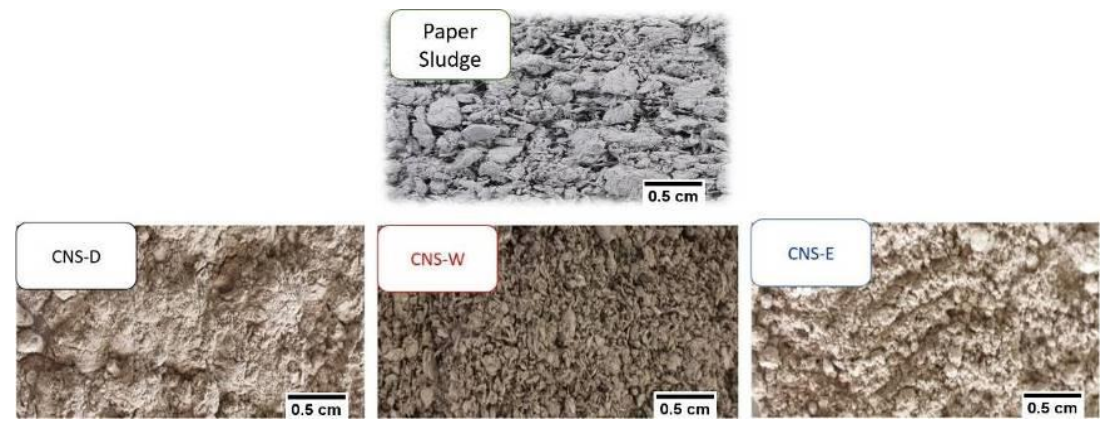

Figure 2: Paper sludge and the powders of samples after milling (CNS-D, CNS-W, and CNS-E).

Note that the CNS-D and CNS-E samples are presented in the former of thinner powders. This occurred because, in the material moistened with water, a formation of agglomerates occurred, possibly due to the hydrogen bonds that formed between the cellulose and the water molecule, as showed in Figure 3 . This resulted in a reduction of effective shocks between the jar, the balls, and the sample, limiting particle size reduction.

Figure 3(a) shows that the agglomerates formed in sample CNS-W have a similar shape and visual sizes to those of the large ceramic balls, and upon breaking these agglomerates, small ceramic balls were found inside (Figure 3(b)). This formation occurred due to the interaction between water and the hydroxyl groups present in the cellulose, forming hydrogen bonds, seeking stabilization of the system (Figure 3(c)) [26]. In the case of the CNS-D, the layer around the balls is due to the cellulose tendency to agglomerate.

The CNS obtained a yield of $89.4 \%, 99.7 \%$ and $96.6 \%$ for CNS-D, CNS-W, and CNS-E, respectively, compared with the initial weight of the treated material. Figure 3(d) shows the ceramic balls after milling for 6 hours. It was observed that the balls used in dry milling were those with the highest content of the adhered 
material, followed by the balls submitted to the milling medium with ethanol, and finally, the balls used in the milling medium with water, which did not show adhered material, but presented the behavior previously discussed.
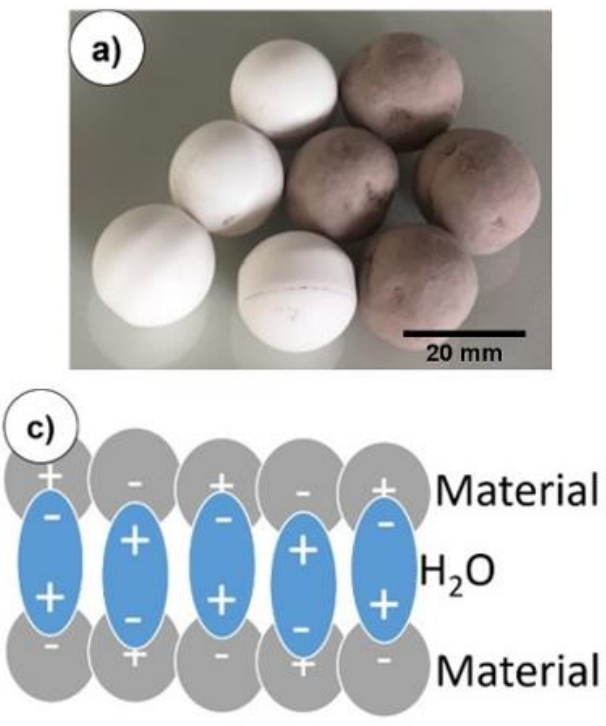

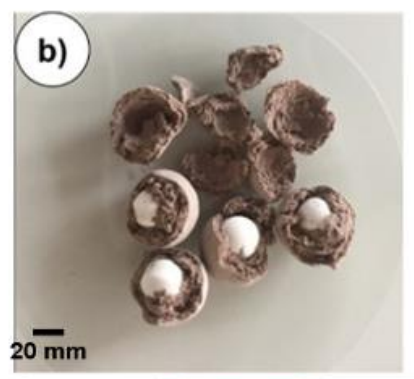

d)

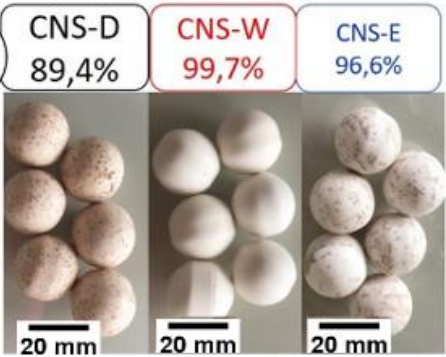

Figure 3: CNS-W sample after milling (a) agglomerates and ceramic balls, (b) breaking of agglomerates, (c) mechanism of formation of agglomerates and (d) the aspect of the balls after each milling and its yield.

The CNS-W yield (89\%) are justified by the loss of material that occurs during dry milling, which is adhered to the walls of the jar and ceramic balls. As for wet media, the problem with the adhered material occurs to a lesser extent [27].

\subsection{Fourier transform infrared spectroscopy (FTIR)}

Fourier transform infrared spectroscopy performed for the analysis of possible changes in chemical structures after the conversion of the treated sample into nanoparticles. The infrared spectra of the CNS-D, CNS-W, CNS-E and Paper sludge are shown in Figure 4.

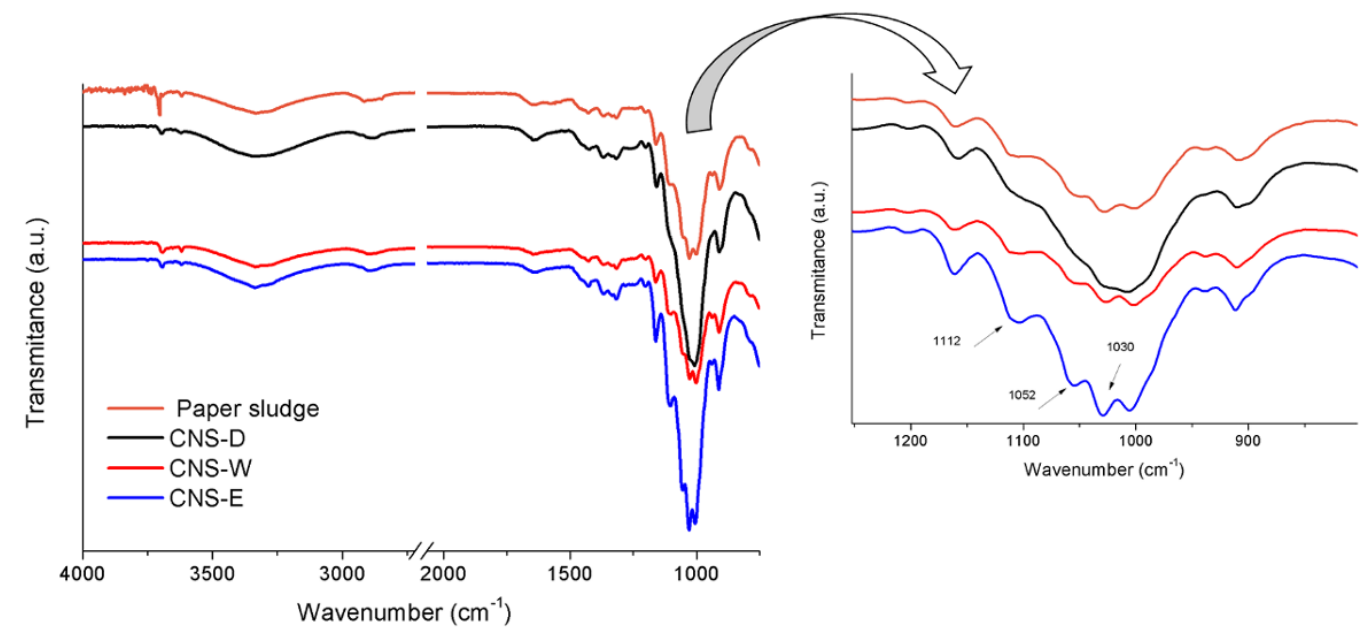

Figure 4: FTIR of samples CNS-D, CNS-W and CNS-E and the Paper Sludge.

Through the FTIR spectra it is possible to observe characteristic peaks of cellulose, around $900 \mathrm{~cm}^{-1}$ ( $-\mathrm{C}-\mathrm{H}$ glycosidic deformation of cellulose), $1000 \mathrm{~cm}^{-1}$ (cellulose vibration $\mathrm{C}-\mathrm{O}$ ) and the band between 3600 and $3000 \mathrm{~cm}^{-1}$ (cellulose $\mathrm{O}-\mathrm{H}$ vibration) are observed for all the samples [27,28]. However, it was found 
variations in the intensity of the peaks after the different milling conditions. From the spectra presented, significant changes in the CNS-D sample are observed, mainly in peaks 1030 (C-O-C pyranose ring vibration), 1052 (cellulose vibration $\mathrm{C}-\mathrm{O}$ ) and $1112 \mathrm{~cm}^{-1}$ (C-O stretching vibration of cellulose ), compared to the other CNSs [29-31]. These peaks in CNS-D tends to disappear, and this indicates a progressive reduction of cellulose crystallinity during the process. These bands, pronounced in CNS-W and CNS-E samples, refer to the typical structures of cellulose, which represents few chemical changes in the structure. It probably occurred because the solvents facilitate intrafibrillar swelling, causing the structure acts as a shock absorber, and thus increasing the damping of the ball impacts on the particles, occurring only breaking the amorphous region of the cellulose [32-35]. Also, the band $900 \mathrm{~cm}^{-1}$ is attributed to C-O-C stretching of glucosidic bond of cellulose and is associated to the amorphous cellulose. All the samples showed a significant amorphous cellulose contribution [35].

It is important to note that the paper residue, as presented above, is an industrial residue with a high content of contaminating components. Thus, no major variations in composition are expected, in addition to the reduction in lignocellulosic components. Nevertheless, this material maintains the cellulosic structure even after the mechanical insulation. This makes it a potential material for reuse, increasing its value added and opening a range of applications possibilities, such as the development of composites for construction and plastic packaging.

\subsection{Thermogravimetric analysis (TGA)}

The thermogravimetric analysis was performed to verify the thermal stability and degradation characteristics of the CNSs. Figure 5 shows the thermogravimetric curves of CNS-D, CNS-W, and CNS-E samples.

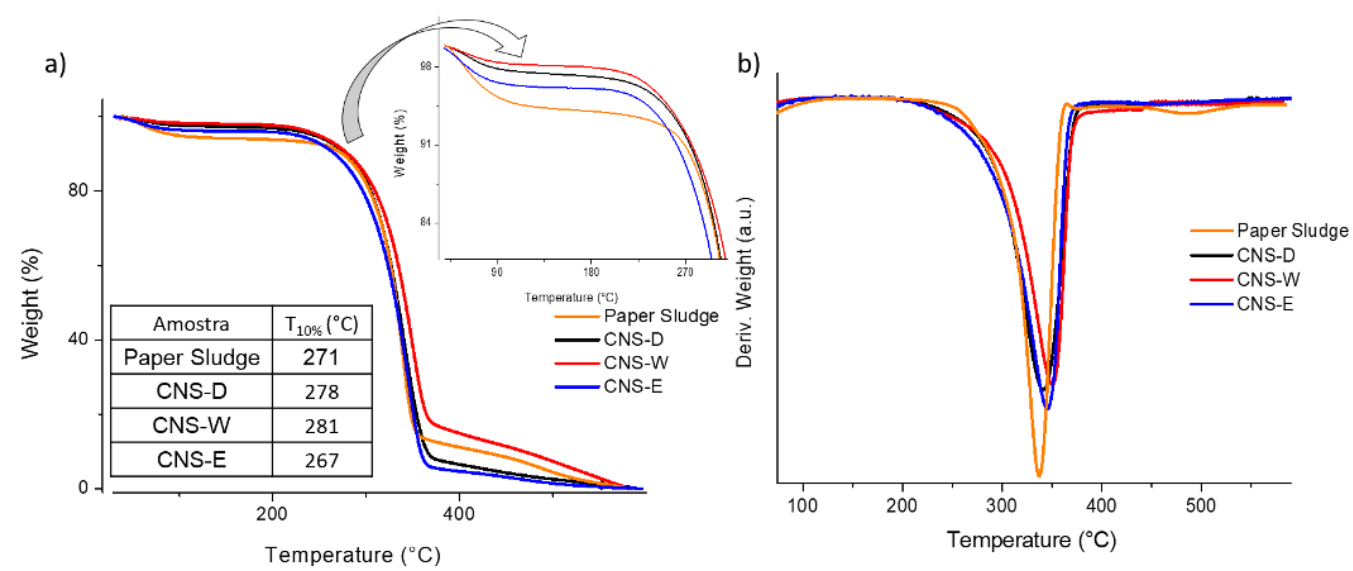

Figure 5: Curves of (a) TGA and (b) DTG of CNSs.

Figure 5 shows the TGA and DTG of Paper Sludge and the CNSs samples. It is observed that all the samples present a small loss of mass $(<10 \%)$ in the range of $50-100{ }^{\circ} \mathrm{C}$, which is related to the evaporation of water and other components of low molar mass of the material. The CNSs present great similarity in the maximum temperature of degradation, as can be observed by the DTG (Figure 5 (b)). The main mass loss event is related to the degradation of cellulose, during which this process occurs dehydration and depolymerization of this compound [36,37].

It is interesting to note that all the nanocelluloses showed a similar thermal behavior than the Paper Sludge. It can be attributed to the methodology used. Mechanical grinding, as reported by Sofla et al., does not modify the cellulose surface in order to catalyze thermal degradation [30]. This result is highly advantageous for future applications of nanocomposites involving melt processing.

The initial temperature of degradation was similar for the three samples of nanocellulose. It occurred because during the milling process there are no chemical reactions, only breaking the cellulose structure, which resulted in similar degradation temperatures [28,33]. The variation in the thermal behavior can be attributed to the small size of the fibers (CNS), which results in a higher specific surface area and a larger number of free end-chains, and these factors catalyze the thermal degradation reaction $[30,36]$.

\subsection{Zeta potential and Dynamic light scattering (DLS)}

The Zeta potential $(\zeta)$ is derived from the measurement of the particle mobility distribution when applied to 
an electric field and is used to evaluate the stability of the nanocellulose suspension in water. The samples had a mean zeta potential value of $-26.7 \pm 2.9 \mathrm{mV},-24.2 \pm 2.6 \mathrm{mV}$ and $-30.8 \pm 0.5 \mathrm{mV}$ for CNS-D, CNS-W, and CNS-E, respectively. The negative values are due to the presence of hydroxyl groups [16].

Based on the presented values, the CNS-E sample can be considered electrostatically stable due to the absolute value higher than $25 \mathrm{mV}$, which cannot be inferred for the CNS-D and CNS-W samples due to the lower values observed [38]. This behavior for CNS-E occurred because ethanol acts as a co-surfactant, i.e., it is responsible for reducing the surface tension of the system, leading to the formation of a more stable interfacial layer and, consequently, increasing the stability of the solution [39]. This stability is related to electrostatic repulsion between the negative groups on the surface of the particles. The CNS-W sample presented the lower absolute value of the zeta potential due to the less free hydroxyls, that it had a hydrogen bond with water, resulting in lower stability. The low stability, that is, the lower absolute value of the zeta potential, results in a higher tendency of agglomeration of the particles since there will be a high surface tension, with which the particles agglomerate seeking their stabilization [26,40,41].

The dynamic light scattering technique was used to determine the size distribution of CNSs. This technique measures the translational diffusion of the particles in the suspension, considering them in spherical form, with Brownian motion. The size distribution curve of the CNSs is shown in Figure 6, and Table 2 shows the minimum, maximum and average sizes for each sample in the nanometer and micrometric region.

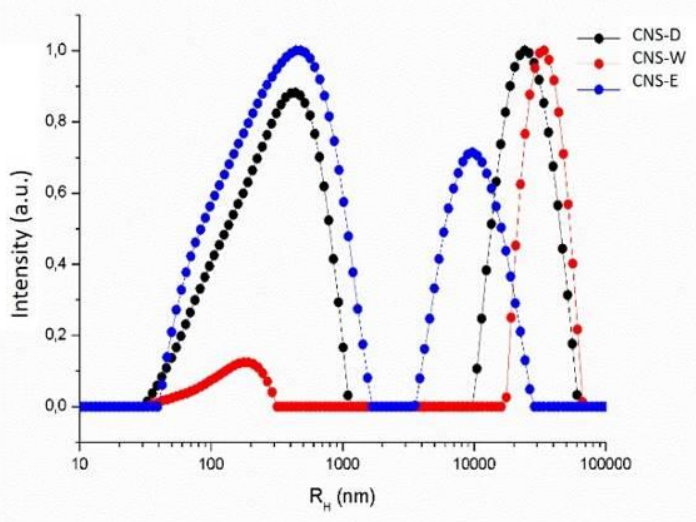

Figure 6: DLS -The curves of scattering intensity as a function of the hydrodynamic radius of the cellulose nanostructures.

The polydisperse curves are due to the formation of a residual cellulose layer on the milling medium (i.e., a layer of cellulose fibers coating the balls), as observed in the ceramic balls after milling (Figure 3(d)). This layer decreases the impact energy of the balls on the particles after a time, making the breaking of the amorphous regions less efficient, producing larger cellulose nanostructures, besides the presence of agglomerates in the solution $[27,30]$.

The CNS-E sample, although good stability in suspension, as seen previously by the analysis of zeta potential, presents great dispersion of size, because the particles suffered lower impact energy of the ceramic balls, due to the damping caused by the solvent, decreasing the efficiency of the process regarding sizes. Nevertheless presented itself as an efficient process, obtaining particles with nanosizes [33]. Thus, regarding size, the CNS-D presented smaller size, but average size similar to CNS-E sample. And the CNS-W presented no significant amount in the nanoscale region, proving the inefficiency of the process. Considering the nanometric region, as reported by other authors, is possible to observe that the average sizes are similar that obtained by different raw materials [40,42-44]. Different than the one evaluated for other nanometric structures, such as carbon nanotubes, it is verified that, when evaluated the nanocellulose, the considered sizes vary between 50 and $500 \mathrm{~nm}$. Moreover, by the results of DLS, as already discussed by other authors, one can be evaluating both nanofibers and nanocrystals, due to the Brownian motion of the particles. Thus, the results obtained in the present study are positive and point to the existence of particles in nanometric dimensions.

It is possible to observe that the CNS-D sample presented a smaller minimum particle size when compared to the other samples. However, the CNS-W sample presented a smaller average particle size at the nanoscale. The CNS-D sample presented a more efficient process of obtaining nanostructures considering the smaller minimum particle size. The CNS-E sample presented similar behavior to the CNS-D, both of which 
have a distribution curve of polydisperse size. The CNS-W presented a larger average size in the micrometric scale, due to the inefficiency of the grinding, in which it formed agglomerates, which did not occur the breakdown of the amorphous regions of the microfibers, so, did not present particles in the nanoscale with significant quantities.

Table 2: Size distribution of CNSs in the nanometric and micrometric region.

\begin{tabular}{c|c|c|c|c|c|c}
\hline & \multicolumn{3}{|c}{ NANOMETRIC REGION } & \multicolumn{3}{c}{ MACROMETRIC REGION } \\
\hline & MINIMUM (nm) & MAXIMUM (nm) & AVERAGE $(\mathbf{n m})$ & MINIMUM $(\boldsymbol{\mu m})$ & MAXIMUM $(\boldsymbol{\mu m})$ & AVERAGE $(\mu \mathrm{m})$ \\
\hline CNS-D & 28 & 1110 & 340 & 9,6 & 65,8 & 24,2 \\
\hline CNS-W & 31 & 317 & 138 & 17,5 & 72,4 & 34,1 \\
\hline CNS-E & 39 & 1678 & 373 & 3,5 & 28,7 & 9,7 \\
\hline
\end{tabular}

From the results of Table 2, it is also possible to observe that the three methodologies present materials in the micrometric scale. It means that although grinding time has been effective in obtaining nanoparticles, the process needs to be improved. Thus, considering the results of DLS, it turns out that the yield cannot be entirely attributed to the nanoparticles.

\subsection{Scanning electron microscopy (SEM)}

After milling the powder samples, morphology was analyzed by SEM, that it was observed in Figure 7. It is possible to see that the CNS-D sample showed morphology more homogenous and smaller size of agglomerates with some non-milled fibers. The sample CNS-W appears with large agglomerates and greater lengths of fibers. It presents mainly micrometric scale, which suggests the low efficiency of the milling, which as discussed previously, showed the formation of agglomerates around the smaller diameter ceramic ball. The CNS-E sample is intermediate, with few clusters, however and longer fibers.

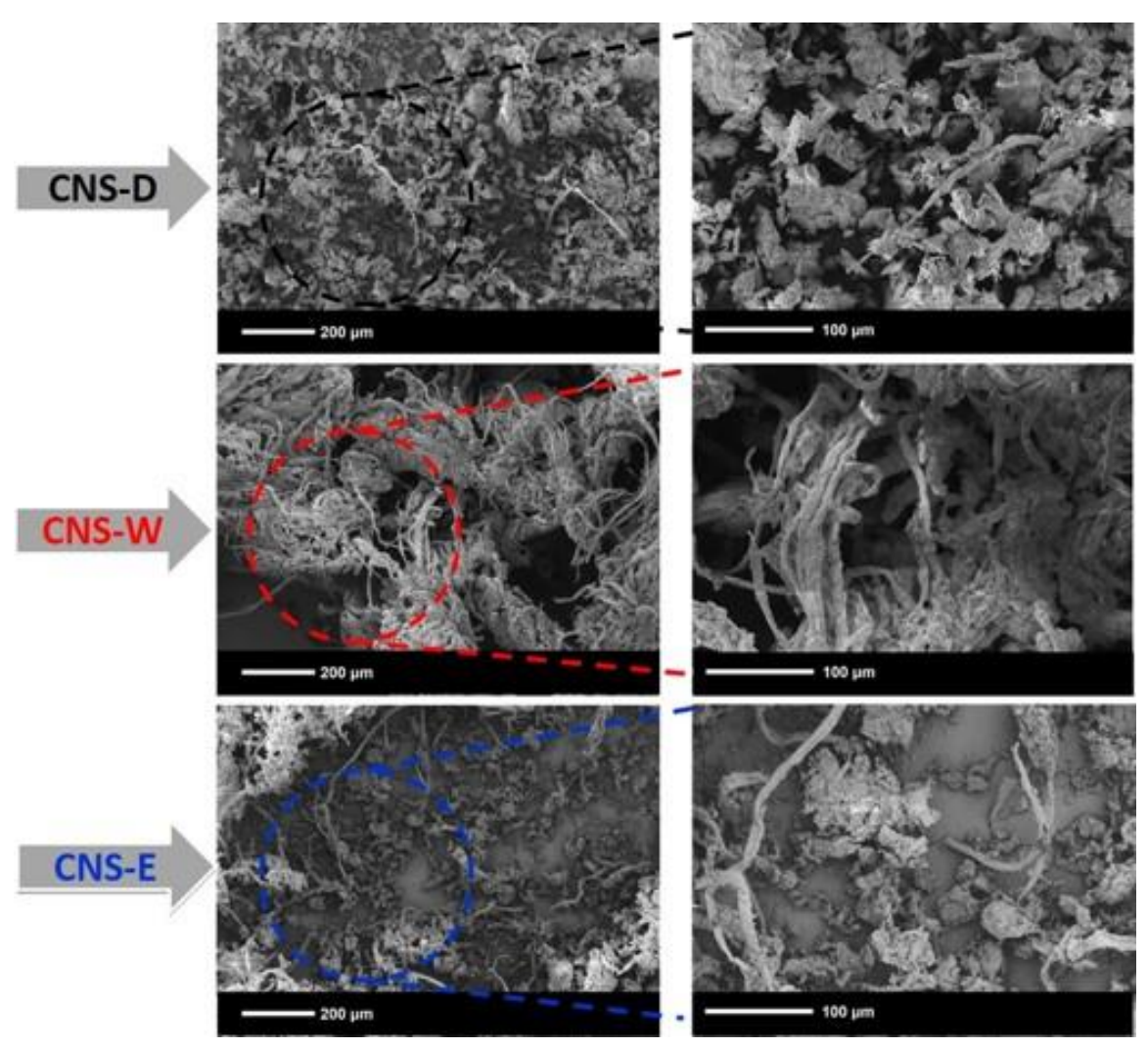

Figure 7: Photomicrographs obtained by SEM of samples after milling (CNS-D, CNS-W, and CNS-E).

The CNS-D samples showed with smaller size when compared with the other samples. However, this 
sample presented agglomerates less fibrillated, and smaller size as observed in the DLS analysis. The CNS$\mathrm{W}$ presented with a longer length and more agglomeration, proving the inefficiency of the process. CNS-E presented intermediate size due to the presence of the solvent. The solvent facilitates intrafibrillar swelling, increasing the surface area available for ball shocks and increase the fibrillation of sample. However, these also act as shock absorbers, reducing the collision force between the balls and the material, and consequently the efficiency of the process in the breaking of the hydrogen bonds and transverse cleavage for conversion in nanostructures $[27,33]$. It is important to note that not only nanocellulose was obtained, but also microstructures. This may be related to the milling time, which could be increased by the ball: sample ratio, or by a combination of isolation methods.

\section{CONCLUSION}

This work obtained cellulose nanostructures (CNS) from the primary waste of the paper industry, using ball mill as isolation methodology. This residue presents great potential as raw material (due to its high cellulosic content) for the isolation of nanocellulose. The treatments were efficient in the removal of non-cellulosic components, and it was observed an increase in cellulose content (98\%), compared to the virgin sample. After the isolation of CNSs, it was observed that the milling moistened with water was inefficient due to the formation of agglomerates. This sample presented low electrostatic stability in solution (low absolute value of zeta potential). The CNS-D sample presented a smaller size of nanostructures; it is considered the most efficient process in the reduction of particle size. Despite the milling efficiency, this sample possibly shows a loss of crystallinity, a result inferred by the FTIR analysis, with a tendency to disappear the peaks related to the crystalline cellulose. Besides, it presents the lowest yield among the samples studied (89.4\%). The CNSE sample showed more significant results. This sample exhibited a mean size distribution like CNS-D, demonstrating an efficient process for size reduction. This sample had better electrostatic stability than the others. The swelling of the material by the solvent leads to the damping of the impacts, does not occur the significant loss of crystallinity, as observed by the FTIR. This milling showed a good yield of $96.6 \%$. It is concluded that the wet milling with ethanol is the best process among the three studied because it presents the formation of CNSs with high milling yield, good electrostatic stability, and no structural and chemical changes.

\section{ACKNOWLEDGMENTS}

The authors are grateful to UFABC, CNPq and the Central Experimental Multiusuário (CEM/UFABC) for technical assistance, and the company Multiverde Papéis Especiais Ltda. by the material supplied.

\section{BIBLIOGRAPHY}

[1] MARTÍNEZ, C., COTES, T., CORPAS, F. A. "Recovering wastes from the paper industry: Development of ceramic materials", Fuel Processing Technology, v. 103, pp. 117-124, 2012.

[2] TUZZIN, G., GODINHO, M., DETTMER, A., ZATTERA, A. J. "Nanofibrillated cellulose from tobacco industry wastes", Carbohydrate Polymers, v. 148, pp. 69-77, 2016.

[3] RIVERA, J. A., LÓPEZ, V. P., CASADO, R. R., et al., "Thermal degradation of paper industry wastes from a recovered paper mill using TGA. Characterization and gasification test", Waste Management, v. 47, pp. 225-235, 2016.

[4] IBÁ 2017 Report 2017 Indústria Brasileira de Árvores ed S 113 (São Paulo) p 80

[5] BAJPAI, P., "Management of Pulp and Paper Mill Waste", In: Management of Pulp and Paper Mill Waste. Cham: Springer International Publishing,. pp. 9-17, 2015.

[6] JOSHI, G., NAITHANI, S., VARSHNEY, V. K., et al., "Synthesis and characterization of carboxymethyl cellulose from office waste paper: A greener approach towards waste management", Waste Management, v. 38, n. 1, pp. 33-40, 2015.

[7] MASTRANTONIO, G., BATTAIOTO, L., JONES, C., et al., "Chemical conversion of paper industry effluents into carboxymethylcellulose", Process Safety and Environmental Protection, v. 94, n. C, pp. 315$321,2015$.

[8] BERGLUND, L., NOËL, M., AITOMÄKI, Y., et al., "Production potential of cellulose nanofibers from industrial residues: Efficiency and nanofiber characteristics", Industrial Crops and Products, v. 92, p. 84-92, 2016.

[9] BRINCHI, L., COTANA, F., FORTUNATI, E., et al., "Production of nanocrystalline cellulose from 
lignocellulosic biomass: Technology and applications", Carbohydrate Polymers, v. 94, n. 1, pp. 154-169, 2013.

[10] KUNAVER, M., ANŽLOVAR, A., ŽAGAR, E. "The fast and effective isolation of nanocellulose from selected cellulosic feedstocks", Carbohydrate Polymers, v. 148, pp. 251-258, 2016.

[11] NADERI, A. "Nanofibrillated cellulose: properties reinvestigated", Cellulose, v. 24, n. 5, p. 1933-1945, 2017.

[12] KARGARZADEH, H., M. SHELTAMI, R., AHMAD, I., et al., "Cellulose nanocrystal: A promising toughening agent for unsaturated polyester nanocomposite", Polymer, v. 56, p. 346-357, 2015.

[13] ANWAR, B., ROSYID, N. H., EFFENDI, D. B., et al., "Isolation of bacterial cellulose nanocrystalline from pineapple peel waste: Optimization of acid concentration in the hydrolysis method", In: AIP Conference Proceedings, Anais.2016.

[14] HABIBI, Y., LUCIA, L. A., ROJAS, O. J. “Cellulose Nanocrystals : Chemistry , Self-Assembly , and Applications", Chemical Reviews, n. 6, p. 3479-3500, 2010.

[15] ABDUL KHALIL, H. P. S., DAVOUDPOUR, Y., ISLAM, M. N, et al., "Production and modification of nanofibrillated cellulose using various mechanical processes: A review", Carbohydrate Polymers, v. 99, p. 649-665, 2014.

[16] SATYAMURTHY, P., VIGNESHWARAN, N. "A novel process for synthesis of spherical nanocellulose by controlled hydrolysis of microcrystalline cellulose using anaerobic microbial consortium", Enzyme and Microbial Technology, v. 52, n. 1, p. 20-25, 2013.

[17] ZHUO, X., LIU, C., PAN, R., et al., "Nanocellulose Mechanically Isolated from Amorpha fruticosa Linn”, ACS Sustainable Chemistry \& Engineering, v. 5, n. 5, p. 4414-4420, 2017.

[18] SOUZA, A. G., KANO, F. S., BONVENT, J. J., et al., "Cellulose Nanostructures Obtained from Waste Paper Industry: A Comparison of Acid and Mechanical Isolation Methods”, Materials Research, p. 1-6, 2017.

[19] SOUZA, A. G., ROCHA, D. B., KANO, F. S., et al., "Valorization of industrial paper waste by isolating cellulose nanostructures with different pretreatment methods", Resources, Conservation and Recycling, v. 143, n. September 2018, p. 133-142, 2019.

[20] BOLUK, Y., DANUMAH, C. “Analysis of cellulose nanocrystal rod lengths by dynamic light scattering and electron microscopy”, Journal of Nanoparticle Research, v. 16, n. 1, 2014.

[21] NG, H.-M., SIN, L. T., TEE, T.-T., et al., "Extraction of cellulose nanocrystals from plant sources for application as reinforcing agent in polymers", Composites Part B: Engineering, v. 75, p. 176-200, 2015.

[22] REBOUILLAT, S., PLA, F. "State of the Art Manufacturing and Engineering of Nanocellulose: A Review of Available Data and Industrial Applications", Journal of Biomaterials and Nanobiotechnology, v. 4, n. April, p. 165-188, 2013.

[23] PAIXÃO, S. M., LADEIRA, S. A., SILVA, T. P., et al., "Sugarcane bagasse delignification with potassium hydroxide for enhanced enzymatic hydrolysis”, RSC Advances, v. 6, n. 2, p. 1042-1052, 2016.

[24] OLIVEIRA, F. B., BRAS, J., PIMENTA, M. T. B., et al., "Production of cellulose nanocrystals from sugarcane bagasse fibers and pith”, Industrial Crops and Products, v. 93, p. 48-57, 2016

[25] THOMPSON, G., SWAIN, J., KAY, M., et al., "The treatment of pulp and paper mill effluent: A review", Bioresource Technology, v. 77, n. 3, p. 275-286, 2001.

[26] DALTIN, D. “Tensoativos: química, propriedades e aplicações”, [s.1.] São Paulo: Blucher, 2011.

[27] BAHETI, V. K., ABBASI, R., MILITKY, J. "Ball milling of jute fibre wastes to prepare nanocellulose", World Journal of Engineering, v. 9, n. 1, p. 45-50, 2012.

[28] CHANDRA, J. C., GEORGE, N., NARAYANANKUTTY, S. K. "Isolation and characterization of cellulose nanofibrils from arecanut husk fibre", Carbohydrate Polymers, v. 142, p. 158-166, 2016.

[29] KALITA, E., NATH, B. K., AGAN, F., et al., "Isolation and characterization of crystalline , autofluorescent , cellulose nanocrystals from saw dust wastes", Industrial Crops and Products, v. 65, p. 550 555,2015

[30] SOFLA, M. R. K., BROWN, R. J., TSUZUKI, T., “A comparison of cellulose nanocrystals and cellulose nanofibres extracted from bagasse using acid and ball milling methods", Advances in Natural Sciences: Nanoscience and Nanotechnology, v. 7, n. 3, 2016

[31] LI, M., WANG, L., LI, D., et al., "Preparation and characterization of cellulose nanofibers from de- 
pectinated sugar beet pulp", Carbohydrate Polymers, v. 102, p. 136-143, 2014.

[32] AVOLIO, R., BONADIES, I., CAPITANI, D., et al., "A multitechnique approach to assess the effect of ball milling on cellulose", Carbohydrate Polymers, v. 87, n. 1, p. 265-273, 2012.

[33] NURUDDIN, M., HOSUR, M., UDDIN, M. J., et al., "A novel approach for extracting cellulose nanofibers from lignocellulosic biomass by ball milling combined with chemical treatment", Journal of Applied Polymer Science, v. 133, n. 9, 2016.

[34] SUNG, S. H., CHANG, Y., HAN, J. "Development of polylactic acid nanocomposite films reinforced with cellulose nanocrystals derived from coffee silverskin", Carbohydrate Polymers, v. 169, p. 495-503, 2017.

[35] LENGOWSKI, E. C., MUNIZ DE, G. I. B., NISGOSKI, S., et al., "Cellulose acquirement evaluation methods with different degrees of crystallinity | Avaliação de métodos de obtenção de celulose com diferentes graus de cristalinidade", Scientia Forestalis/Forest Sciences, v. 41, n. 98, p. 185-194, 2013

[36] PASCHOAL, G. B., MULLER, C. M. O., CARVALHO, G. M., et al., "Isolation and characterization of nanofibrillated cellulose from oat hulls", Quimica Nova, v. 38, n. 4, p. 478-482, 2015.

[37] CHEN, Y. W., LEE, H. V. "Revalorization of selected municipal solid wastes as new precursors of "green" nanocellulose via a novel one-pot isolation system: A source perspective", International Journal of Biological Macromolecules, v. 107, p. 78-92, fev. 2018.

[38] MORAIS, J. P. S., ROSA, M. D. F., SOUZA FILHO, M. D. S. M., et al.,"Extraction and characterization of nanocellulose structures from raw cotton linter", Carbohydrate Polymers, v. 91, n. 1, p. 229-235, 2013.

[39] SILVA, J. D. F., SILVA, Y. P., PIATNICKI, C. M. S., et al., "Microemulsions: components, characteristics, potentialities in food chemistry and other applications", Química Nova, v. 38, n. 9, p. 11961206, 2015.

[40] LIU, C., LI, B., DU, H., et al., "Properties of nanocellulose isolated from corncob residue using sulfuric acid, formic acid, oxidative and mechanical methods", Carbohydrate Polymers, v. 151, p. 716-724, 2016.

[41] TONOLI, G. H. D., TEIXEIRA, E. M., CORRÊA, A. C., et al., "Cellulose micro/nanofibres from Eucalyptus kraft pulp: Preparation and properties", Carbohydrate Polymers, v. 89, n. 1, p. 80-88, 2012.

[42] ABRAHAM, E., DEEPA, B., POTHAN, L. A., "Extraction of nanocellulose fibrils from lignocellulosic fibres: A novel approach", Carbohydrate Polymers, v. 86, n. 4, p. 1468-1475, 2011.

[43] PHANTHONG, P., GUAN, G., MA, Y., "Effect of ball milling on the production of nanocellulose using mild acid hydrolysis method", Journal of the Taiwan Institute of Chemical Engineers, v. 60, p. 617-622, 2016.

[44] WANG, Y., WEI, X., LI, J., et al., "Homogeneous isolation of nanocellulose from eucalyptus pulp by high pressure homogenization", Industrial Crops and Products, v. 104, n. March, p. 237-241, 2017.

\section{ORCID}

Fabiany Sayuri Kano

Alana Gabrieli de Souza

Derval dos Santos Rosa https://orcid.org/0000-0001-6592-9134

https://orcid.org/0000-0002-9656-6716

https://orcid.org/0000-0001-9470-0638 